Quality of life-Two paediatric patients were excluded from the assessment of quality of life. The age ranges and average ages of the remaining patients in the three groups were: blind patients 25-64 years, average 40.4 ; sighted diabetic patients $31-63$ years, average $46 \cdot 7$; non-diabetic patients $18-84$ years, average $53 \cdot 0$. From the records a detailed summary of each patient was prepared and discussed by a conference of doctor, nurses, social worker, and dietitian. No specialised psychological data were used other than a detailed familiarity with each patient and closest relative. We agreed that continuous ambulatory peritoneal dialysis had not been worth while in eight non-diabetic patients and four sighted diabetics. Reasons varied but included patient resentment, recurrent peritonitis, failure to achieve self care, failure to achieve a satisfactory level of wellbeing, and early failure of the technique, causing the treatment to be abandoned. By contrast, we considered that continuous ambulatory peritoneal dialysis had been worth while in all the blind patients. One blind patient remained depressed but continued to do the exchanges himself without difficulty and refused to return to haemodialysis. Only one blind patient could not manage self care, because of neuropathy and dependency. His wife found continuous ambulatory peritoneal dialysis much less demanding on her than bringing him for haemodialysis, and so we considered the treatment worth while. For the rest of the blind patients the conclusion was positive. All returned to their previous employment, home making, or studying full time and functioned at the same level as before becoming ill with renal failure.

Other aspects of treatment-Biochemical and physical changes, blood sugar control, complications other than peritonitis, and variations in blood pressure are detailed elsewhere. ${ }^{6}$

\section{Discussion}

All the patients in this series were offered treatment and chose continuous ambulatory peritoneal dialysis. Most of them had received haemodialysis and all were considered for transplantation. Having chosen continuous ambulatory peritoneal dialysis, most of the blind patients achieved exemplary self care over extended periods. No better demonstration of a strong will to live, a keen interest in their own wellbeing, and a wish not to burden others could be asked of any patient. These patients obviously needed excellent training by skilled nurses and continuing support by the medical team. In return the team received much professional satisfaction.

Probably the apathy and depression of blind diabetics with renal failure arise from their belief that they are thought of as hopeless cases. Any lingering sentiment that blindness in itself contraindicates treatment paralyses the doctor-patient relationship, to which I can testify, from the evolution of my own attitude. Of far more importance in inhibiting treatment in Britain must surely be the shortage of facilities and staff. There are many valid reasons for withholding treatment in diabetic patients with multiple complications, but when the blind patient chooses to have treatment it usually proves worth while.

\section{References}

${ }^{1}$ Multicentre Study Group. Combined report on international dialysis and renal transplantation in Europe. Proc Eur Dial Transplant Assoc $1981 ; 18: 2-58$

- Medical Services Study Group of the Royal College of Physicians. Deaths from chronic renal failure under age 50. Br Med $\mathcal{f} 1981$;283:283-6.

${ }^{3}$ Anonymous. Audit in renal failure: the wrong target? $\mathrm{Br} M e d \mathcal{F}_{1981}$; $283: 261-2$

${ }^{4}$ Havener WH. Synopsis of ophthalmology. St Louis: C V Mosby Co, 1975:567.

${ }^{5}$ Lane T, Stroshal V, Waldorf P. Standards of care for the CAPD patient. Nephrological Nurse 1982;4, No 5:34-45.

${ }^{6}$ Flynn CT, Shadur CA. A comparison of continuous ambulatory peritoneal dialysis in diabetic and nondiabetic patients. American fournal of Kidney Diseases 1981;1:15-23.

(Accepted 10 June 1983)

\title{
Response of pulmonary circulation to oral pirbuterol in chronic airflow obstruction
}

\author{
ANDREW PEACOCK, C BUSST, K DAWKINS, D M DENISON
}

\begin{abstract}
The effects of the oral beta agonist pirbuterol on pulmonary haemodynamics and gas exchange were studied in nine patients with severe irreversible airflow obstruction and moderate arterial hypoxaemia. After administration of $15 \mathrm{mg}$ pirbuterol pulmonary vascular resistance fell by $19 \%$ but cardiac output rose by $24 \%$, so that pulmonary arterial pressure showed no significant change. Systemic arterial oxygen pressure fell by $7 \%$,
\end{abstract}

Lung Function Unit and Department of Cardiology, Brompton Hospital, London SW3

ANDREW PEACOCK, MPHIL, MRCP, registrar in thoracic medicine

C BUSST, BSC, research assistant

$\mathrm{K}$ DAWKINS, MB, MRCP, senior registrar in cardiology

D M DENISON, PHD, MRCP, professor of clinical physiology, University of London, and director of lung function unit

Correspondence to: Dr Andrew Peacock, Lung Function Unit, Brompton Hospital, London SW3 6HP. limiting the rise in oxygen delivery to $21 \%$. All changes were significant at the $2 \%$ level.

These results show that pirbuterol dilates the pulmonary bed at the cost of a slight worsening of gas exchange, which is compensated by an independent rise in blood flow.

\section{Introduction}

In patients with chronic airflow obstruction pulmonary hypertension is a bad prognostic sign.$^{1-4}$ Long term oxygen treatment reduces mean pulmonary artery pressure in these patients, and in less severely affected patients oxygen improves the prognosis. ${ }^{56}$ Probably the oxygen acts by reversing hypoxic vasoconstriction. If so, other pulmonary vasodilators that are easy to administer long term might have the same effect. We therefore studied the effects of the acute administration of oral pirbuterol on pulmonary haemodynamics and gas exchange in nine patients who had severe airflow obstruction but only moderate hypoxaemia. Pirbuterol is a new beta agonist with both inotropic and vasodilative properties ${ }^{7}$ which has been showal to be a useful adjunct to digoxin and diuretics in left heart failure. ${ }^{8-11}$ 


\section{Patients and methods}

We studied nine patients with chronic bronchitis (seven men, two women; age 45-75 years) whose mean forced expiratory volume in one second averaged $28 \%$ of predicted values (range $15-48 \%$ ). They had arterial hypoxaemia (mean arterial oxygen pressure $\left(\mathrm{PaO}_{2}\right)$ 8.4 (SE 0.5) $\mathrm{kPa} ; 63$ (SE 4) $\mathrm{mm} \mathrm{Hg}$ ) but were normocapnic (mean arterial carbon dioxide pressure $\left(\mathrm{PaCO}_{2}\right) 5.5$ (SE 0.3) $\mathrm{kPa} ; 41$ (SE 2) $\mathrm{mm} \mathrm{Hg}$ ). None of the patients had had an infective exacerbation of their illness in the two months before the study and all had been receiving the same maintenance treatment (bronchodilators, steroids, diuretics) for at least one month. Oral beta agonists and methylxanthine preparations were stopped 24 hours before the study and inhalers were stopped on the day of the study.
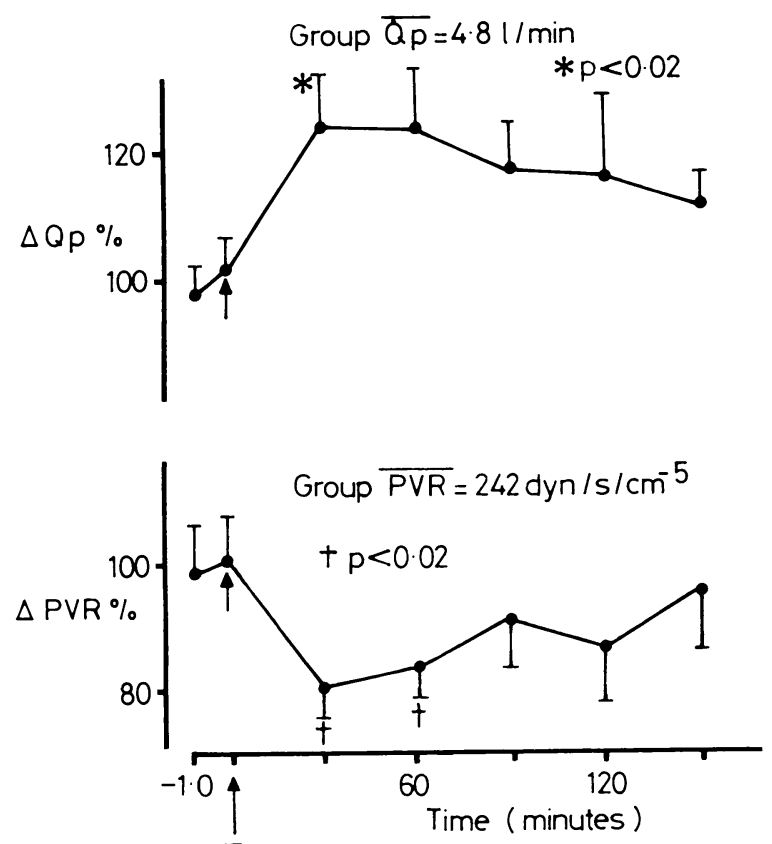

Pirbuterol $15 \mathrm{mg}$

FIG 1-Percentage changes from mean baseline results for cardiac output (Qp) and pulmonary vascular resistance (PVR) before and after pirbuterol. Because pulmonary artery pressure did not change changes in pulmonary vascular resistance mirrored changes in cardiac output. (Points and bars are means and SE.)

After chest $x$ ray examination to exclude new pulmonary disease and baseline lung function tests, each patient was catheterised with a Swan-Ganz balloon catheter to measure pulmonary artery pressure (PAP) and pulmonary artery wedge pressure (PAW). They also had radial artery lines to allow direct measurement of systemic arterial pressure. PAP and PAW were measured while the subjects were in a semisupine position with the transducers placed at a level $5 \mathrm{~cm}$ below the sternal angle. Because of the wide swings in these pressures that occur with respiration in patients with airflow obstruction all measurements were made with the subjects holding the breath at functional residual capacity. Heart rate was measured from an electrocardiogram. Paired samples of mixed venous and arterial blood were taken from the appropriate lines to measure $\mathrm{Po}_{2}, \mathrm{PCO}_{2}$, and oxygen saturation. Samples were rejected if one of the pair varied by more than $0.5 \mathrm{kPa}$ ( $4 \mathrm{~mm} \mathrm{Hg}$ ) from the other.

Oxygen consumption $\left(\mathrm{VO}_{2}\right)$ was determined by analysis of expired gas using a mass spectrometer (Centronics MGA 200), and cardiac output (Qp) was calculated from the $\mathrm{Vo}_{2}$ and oxygen content of the blood upstream and downstream of the lungs (direct Fick). Pulmonary vascular resistance (PVR) was calculated from the formula: PVR = (PAP - PAW)/Qp. The coefficient of oxygen delivery (COD), which measures the adequacy of the oxygen supply pumped by the heart to the tissues, was calculated as $\mathrm{COD}=\left(\mathrm{Qp} \times \mathrm{CaO}_{2}\right) / \mathrm{Vo}_{2}$, where $\mathrm{CaO}_{2}$ is the oxygen content of arterial blood.

Haemodynamic measurements were made continuously until no further change was observed. Two sets of baseline measurements were then performed 10 minutes apart and all subsequent changes determined in relation to the mean of these two values. If the baseline PAP was normal (three patients) subjects were exercised by three minutes of straight leg raising to look for an exercise induced rise in PAP. Once the baseline values had been established (or re-established) $15 \mathrm{mg}$ pirbuterol was given by mouth and measurements made every 30 minutes for 150 minutes. In the three patients who had been exercised the exercise was repeated at 100 minutes to see whether pirbuterol could prevent an exercise induced rise in PAP. Because of the wide variation in baseline values among our subjects for all measured variables results were calculated as percentage change from baseline values. Results were analysed statistically by Student's $t$ test on the percentage differences from baseline.

\section{Results}

Figures 1-3 give the results for PVR, Qp, PAP, heart rate, systemic arterial pressure, $\mathrm{PaO}_{2}$, and $\mathrm{COD}$. In these figures each point and associated bar represent the mean and standard error of the mean for the group. Above each graph is the mean of the baseline measurements for the group. PVR (fig 1), which averaged $242 \mathrm{dyn} / \mathrm{s} / \mathrm{cm}^{-5}$ for the group (normal approximately $150 \mathrm{dyn} / \mathrm{s} / \mathrm{cm}^{-5}$ ), fell by $19 \%$ $(\mathrm{SE} 6 \%)$ at 30 minutes $(\mathrm{p}<0.02)$ and was still reduced by $16 \%$ at
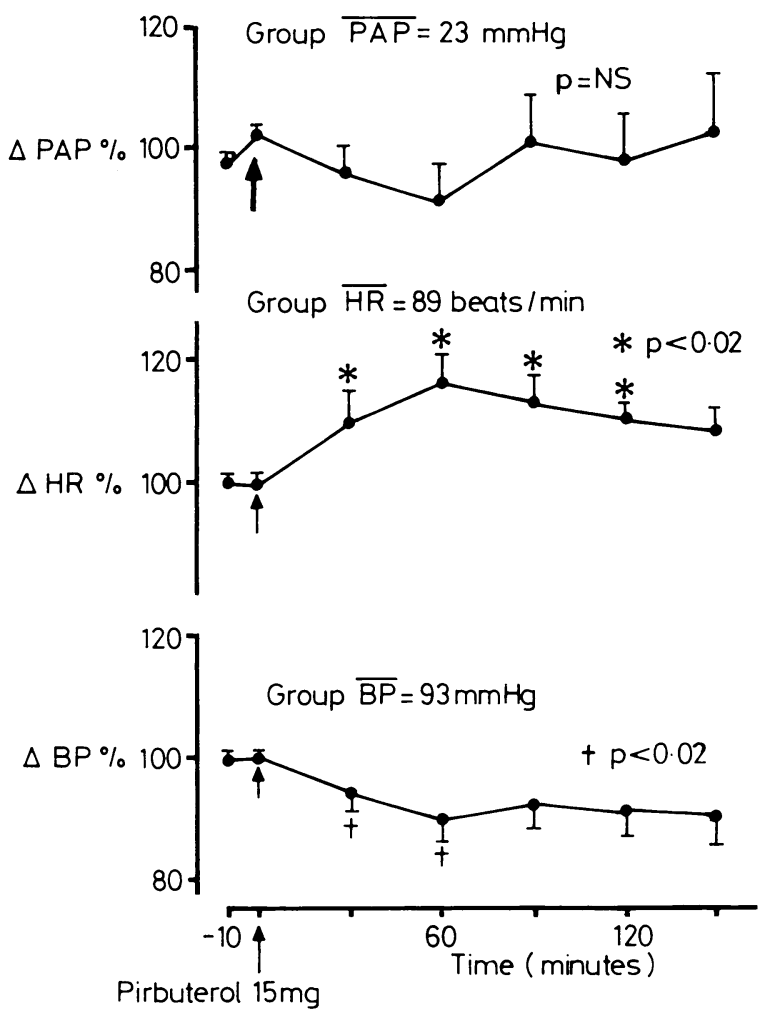

FIG 2-Percentage changes from mean baseline measurements of pulmonary artery pressure (PAP), heart rate (HR), and systemic blood pressure (BP) before and after pirbuterol. Despite lack of change in pulmonary artery pressure changes in heart rate and systemic blood pressure indicated that vasodilatation had occurred. (Points and bars are means and SE.)

60 minutes. The mean $\mathrm{Qp}$ for the group (fig 1 ) was $4.81 / \mathrm{min}$, and on average this rose by $24 \%(\mathrm{SE} 8 \%$ ) at 30 minutes $(\mathrm{p}<0.02)$. The rise was sustained at 60 minutes.

Figure 2 gives the results for PAP, heart rate, and systemic blood pressure. The mean PAP for the group was moderately raised at $23 \mathrm{~mm} \mathrm{Hg}$. After pirbuterol the PAP fell at 30 and 60 minutes but these falls did not reach significance. The rise in PAP with exercise that occurred in all three patients in whom it was measured, however, was prevented in two of them. Heart rate rose at 30 minutes, reaching a maximum at 60 minutes $(p<0.02)$. This rise was accompanied by a fall in systemic blood pressure $(\mathrm{p}<0.05)$, indicating that systemic vasodilatation had taken place, which reached a maximum at 60 minutes.

$\mathrm{PaO}_{2}$ (fig 3) fell by $7 \%$ (SE $2.4 \%$ ) at 90 minutes. The fall was significant $(p<0.02)$. Because there was a rise in $Q p$, however, the COD rose from an average of 3.68 at baseline (normal approximately 4 ) 
to an average of 4.46 at 30 minutes. This rise of $21^{\circ} \circ\left(\mathrm{SE} 6^{\circ}{ }_{\circ}^{\circ}\right)$ was significant $(p<0.02)$ and was accompanied by a $5 \%$ rise in mixed venous oxygen pressure, which was also significant $(p<0.05)$.

Spirometry was not repeated after the acute administration of pirbuterol but was repeated after the patients had been receiving the drug for two weeks. Functionally significant bronchodilatation was seen in only one of the nine subjects.
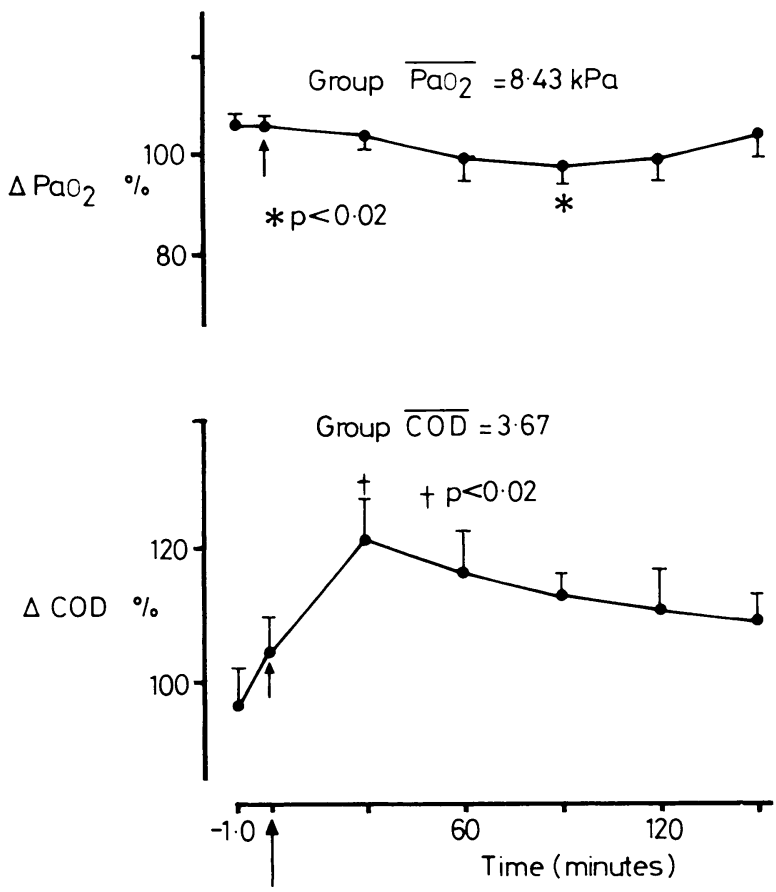

Pirbuterol $15 \mathrm{mg}$

FIG 3-Percentage changes from mean baseline results for arterial oxygen pressure $\left(\mathrm{PaO}_{2}\right)$ and coefficient of oxygen delivery (COD) before and after pirbuterol. Coefficient of oxygen delivery rose at 30 minutes and rise was sustained throughout study despite slight fall in arterial oxygen pressure.

Conversion: SI to traditional units- $-\mathrm{PaO}_{2}: 1 \mathrm{kPa} \approx 7.5 \mathrm{~mm} \mathrm{Hg}$.

\section{Discussion}

This study shows that the acute administration of $15 \mathrm{mg}$ pirbuterol by mouth to patients who have irreversible airflow obstruction but only moderate arterial hypoxaemia causes a significant fall in pulmonary vascular resistance at the cost of a significant fall in arterial oxygen pressure.

The mean cardiac output of our patients was $4.8 \mathrm{l} / \mathrm{min}$, which is normal. This is a typical finding in patients with chronic airflow obstruction. Pirbuterol caused a rise in cardiac output without any significant change in pulmonary artery pressure. These results are in line with those of other studies (including two from our laboratory ${ }^{12}{ }^{13}$ ) where vasodilative drugs were given to patients with primary and secondary pulmonary hypertension. The fall in pulmonary vascular resistance was therefore accompanied by an increase in cardiac work, which is a function of cardiac output and pulmonary artery pressure. Whether the beneficial effects of a decrease in pulmonary vascular resistance are outweighed by the possibly harmful effects of an increase in cardiac work when drugs such as pirbuterol are given long term remains to be seen. The advantage of preventing an exercise induced rise in pulmonary artery pressure is at present theoretical.

The haemodynamic effects of pirbuterol occurred at the expense of a small but significant fall in arterial oxygen pressure. This fall is not surprising, because alveolar hypoxia causes a functional vasoconstriction to underventilated areas of the lung. Reversal of this vasoconstriction would result in worsening of ventilation-perfusion mismatch with adverse consequences for gas exchange. The fall in arterial oxygen pressure in our patients was unimportant because they were on the plateau of the oxygen dissociation curve. In patients with severe daytime hypoxaemia or those who desaturate severely at night a similar fall would have a greater impact on arterial oxygen content.

Bergofsky ${ }^{14}$ argued that oxygen delivery to the tissues may be more important than arterial oxygen pressure. In our patients there was a significant rise in oxygen delivery despite the fall in arterial oxygen pressure because of the increase in cardiac output. This rise in coefficient of oxygen delivery resulted in a useful increase in mixed venous oxygen pressure, but it was impossible to determine which tissue or even which organ received the benefit of the increase in oxygen delivery.

Bergofsky also argued that an increase in cardiac output may be the distinguishing feature of those patients with chronic airflow obstruction who survive the longest. He suggested that attempts should be made to maintain cardiac output in patients with chronic bronchitis and emphysema by giving them drugs with inotropic or afterload reducing properties, or both. Pirbuterol is such a drug. Long term studies are needed to see whether its use will improve survival in these patients.

We are grateful to Pfizer (UK) Ltd, who provided the supplies of pirbuterol and supported the cost of the trial.

\section{References}

1 Stuart-Harris $\mathrm{CH}$. Pulmonary hypertension and chronic obstructive bronchitis. Am Rev Respir Dis 1968;97:9-16.

2 Ude AC, Howard P. Controlled oxygen therapy and pulmonary heart failure. Thorax $1971 ; 26: 572-8$.

${ }^{3}$ Diener CF, Burrows B. Further observations on the course and prognosis of chronic obstructive lung disease. Am Rev Respir Dis 1975;111:719-24.

4 Weitzenblum E, Hirth C, Ducolone A, Mirhom R, Rasaholinjanahary J, Ehrhart $M$. Prognostic value of pulmonary artery pressure in chronic obstructive lung disease. Thorax $1981 ; 36: 752-8$.

${ }^{5}$ Medical Research Council Working Party. Long term domiciliary oxygen therapy in chronic hypoxic cor pulmonale complicating chronic bronchitis and emphysema. Lancet 1981 ;i:681-6.

${ }^{6}$ Noctunal Oxygen Therapy Trial Group. Ann Intern Med 1980;93:391-8.

' Gold FL, Horowitz LD. Hemodynamic effects of pirbuterol in conscious dogs. Am Heart $\mathcal{F} 1981 ; 102: 591-6$.

* Awan NA, Needham K, Evenson MK, et al. Therapeutic efficacy of oral pirbuterol in severe chronic congestive heart failure: acute hemodynamic and long-term ambulatory evaluation. Am Heart $\mathcal{f} 1981 ; 102$ : 556-63.

${ }^{9}$ Awan NA, Needham KE, Evenson MK, Mason DT. Comparison of hemodynamic actions of pirbuterol and dobutamine on cardiac function in severe congestive heart failure. Am $\mathcal{F}$ Cardiol 1981 ;47:665-9.

"Canepa-Anson R, Dawson JR, Kuan P, et al. Single-dose and doseresponse studies with oral pirbuterol, a new beta agonist in chronic heart failure. Am Heart $\mathcal{F} 1981$;102:578-83.

$"$ Colucci WS, Alexander RW, Mudge GH, et al. Acute and chronic effects of pirbuterol on left ventricular ejection fraction and clinical status in severe congestive heart failure. Am Heart 7 1981;102:564-8.

12 Honey M, Cotter L, Davies N, Denison DM. The clinical and haemodynamic effects of diazoxide in primary pulmonary hypertension. Thorax 1980;35:269-76.

13 Davies NJH, Shinebourne EA, Scallan MJ, Sopwith TA, Denison DM A study of pulmonary vascular resistance in children with congenital heart disease. Thorax (in press).

${ }^{14}$ Bergofsky EH. Tissue oxygen delivery and cor pulmonale in chronic obstructive pulmonary disease. $N$ Engl f Med 1983;308:1092-4.

(Accepted 18 August 1983)

ANGELICA WATER THE GREATER COMPOSITION- "Take of Angelica two pounds, Annis seed half a pound, Coriander and Caraway seeds, of each four ounces, Zedoary bruised, three ounces: steep them twenty four hours in six gallons of small wine, then draw out the spirit, and sweeten it with sugar."

It comforts the heart, cherishes the vital spirits, resists the pestilence, and all corrupt airs, which indeed are the natural causes of epidemical diseases, the sick may take a spoonful of it in any convenient cordial, and such as are in health, and have bodies either cold by nature, or cooled by age, may take as much either in the morning fasting, or a little before meat. (Nicholas Culpeper (1616-54) The Complete Herbal, 1850.) 